\title{
Experimental Investigation of Die Drool and Slip-stick Phenomena during HDPE Polymer Melt Extrusion
}

\author{
Jan Musil $^{\mathrm{a}}$, Martin Zatloukal ${ }^{\mathrm{a}}$, Tim Gough ${ }^{\mathrm{b}}$ and Mike Martyn ${ }^{\mathrm{b}}$ \\ ${ }^{a}$ Centre of Polymer Systems, Polymer Centre, Tomas Bata University in Zlin, \\ nam. T. G. Masaryka 5555, 76001 Zlin, Czech Republic \\ ${ }^{b}$ IRC in Polymer Engineering, School of Engineering, Design and Technology, University of Bradford, \\ Richmond Road, BD7 1DP, Bradford, United Kingdom
}

\begin{abstract}
In this work, two slightly different batches of one commercial linear HDPE polymer melt were rheologically characterized and then extruded through two specially designed dies (annular and slit) in order to investigate die drool as well as slip-stick phenomena. Flow birefringence stress visualization inside the slit die was also performed. It has been revealed that lower elasticity and both shear and extensional viscosities reduce accumulated drool mass at the die exit face and also correlation between appearance and intensity of both slip-stick and die drool phenomena was discovered.
\end{abstract}

Keywords: Die drool, Slip-stick, Flow instabilities, Flow birefringence, Shear viscosity, Extensional viscosity, Extrusion.

PACS: 47.50.Ef, 47.50.Gj, 47.80.Jk, 83.50.Jf, 83.50.Uv, 83.60.Wc, 83.80.Sg, 83.85.Cg, 83.85.Rx, 83.85.Ei, 83.85.Jn, 83.80.Sg

\section{INTRODUCTION}

Extrusion of non-Newtonian polymer melts is usually limited by a range of unwanted flow phenomena [1-3] which are not fully understood yet. One of them is so called die drool phenomenon (also termed as drooling, die lip build up, die bleed, die plate out or die deposit).

Die drool phenomenon is in extrusion art known as undesirable spontaneous accumulation of polymer melt at the die exit face. In this way accumulated polymer material (generally called "drool") then builds up into a large (toroidal shape in the case of annular extrusion die) usually degraded mass which periodically breaks away from the die, completely (or partly) encloses extruded product, sticks perseveringly onto extrudate surface and thus damage it.

This nasty phenomenon limits melt extrusion of polyolefins, PVC, PET, polycarbonates, polystyrenes or filled polymers. The simplest solution often used in the polymer extrusion industry consists in frequently manual cleaning procedure of die exit face. However, in the case of tubular extrusion processes (like film blowing, pipe or profile extrusion or cable sheathing) drool mass builds up not only at outside faces but also at the inner ones. Thus, in this case it is virtually impossible to remove it. 
Wide range of possible die drool sources like low molecular fractions of extruded polymer, volatilies, fillers, die swell, die design, etc. can be found in open literature [4-10]. Further, three recently published works are focused on die drool phenomenon during HDPE extrusion. In the first [11] influence of long chain branching on drool mass is discussed, in the second, [12] thermal degradation in extruder as other possible die drool source is investigated and in the third [13], flow-induced low molecular species fractionation inside the extrusion die as a fundamental source of die drool in the case of HDPE extrusion is proved.

Another involuntary phenomenon following especially extrusion of HDPE polymer melts is slip-stick. This instability appears at very narrow processing window (depending on temperature and flow rate for given polymer melt) in which pressure in extrusion die oscillates between two extreme values, although the imposed flow rate is kept constant. A lot of works focused on this instability have been already published [14-17] however, only one small notice about correlation between slip-stick and die drool phenomena can be found in [18].

Thus, the main goal of this experimental work is deeper investigation of possible correlation between two typical HDPE melt extrusion instabilities - die drool and slip-stick. This goal is reached by utilizing of two slightly different batches of one commercial HDPE polymer melt.

\section{EXPERIMENTAL}

The experimental work is divided into three parts. Firstly, rheological characterization of two slightly different batches of one commercial HDPE polymer material secondly, their extrusion through specially designed annular capillary die, with the aim to evaluate their die drool tendencies and finally, their extrusion through specially designed slit visualization cell in order to visualize the stress at slip-stick region inside the slit near the wall where die drool is formed.

\section{Rheological Characterization}

Two slightly different batches (HDPE Liten FB 29 E2009 32204479 and HDPE Liten FB 29 E2009 5498 7937) of one HDPE polymer (HDPE Liten FB 29, film grade, Chemopetrol, Czech Republic) were chosen for our experimental research.

Linear viscoelastic property (complex viscosity $\eta^{*}$ ) and transient first normal stress coefficient $\psi_{1}$ were measured on Advanced Rheometric Expansion System (ARES 2000 ) in parallel plates geometry mode. Transient uniaxial extensional viscosity $\eta_{\mathrm{E}}$ was determined by SER Universal Testing Platform (SER-HV-A01 model) attached to ARES 2000. All measurements were performed at $190^{\circ} \mathrm{C}$ and they are provided in Figures 1 to 3. As can be seen, HDPE Liten FB 29 E2009 32204479 has higher viscosity and elasticity and also uniaxial extensional viscosity than HDPE Liten FB 29 E2009 5498 7937. It is also evident that both polymers are virtually linear (without strain hardening peaks appearing on transient uniaxial extensional viscosity curves). 


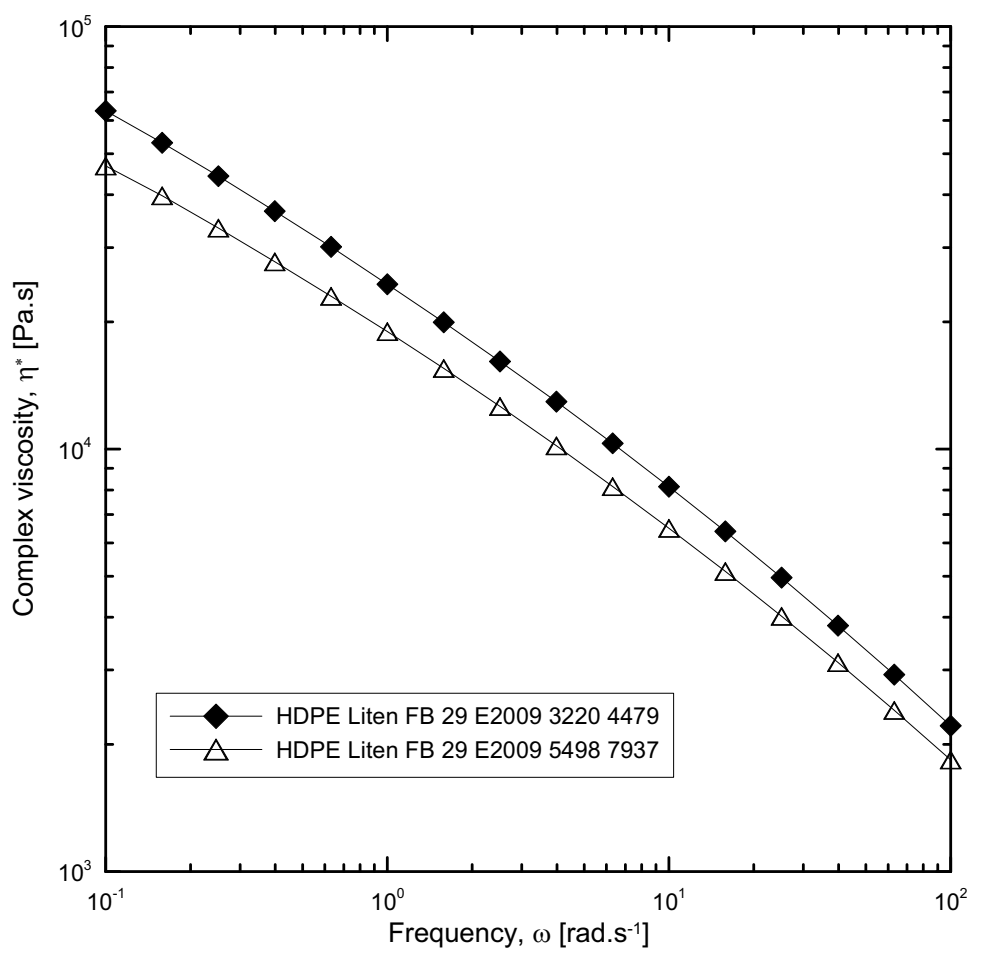

FIGURE 1. Complex viscosity for both investigated HDPEs.

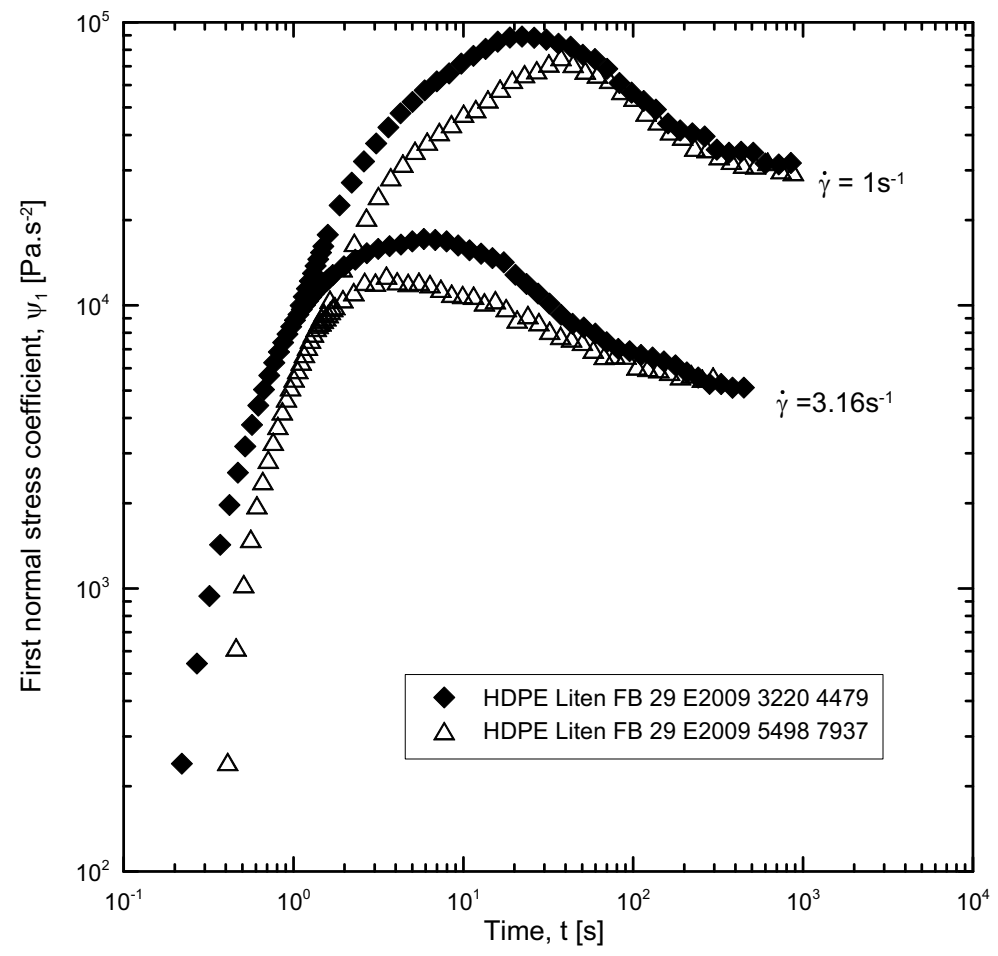

FIGURE 2. Transient first normal stress coefficient for both investigated HDPEs. 


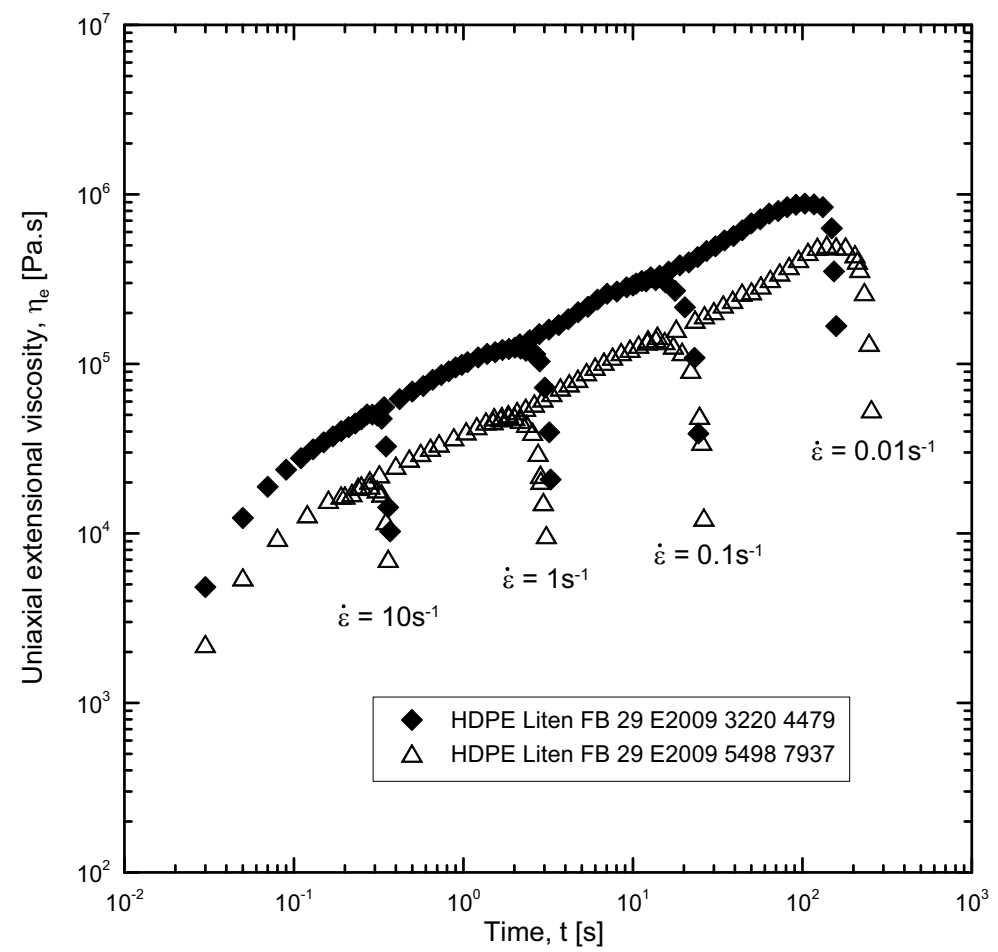

FIGURE 3. Transient uniaxial extensional viscosity for both investigated HDPEs.

\section{Die Drool Measurements}

Evaluation of drool tendencies of both HDPE polymer melts were performed on laboratory extrusion line (schematic 3D section view is depicted in Figure 4) consisted from:

- conventional Brabender Plasti-Corder 2000 (Brabender, Germany) single screw extruder with diameter of $30 \mathrm{~mm}$ and length of 25D (standard single-thread screw with compression ratio 4:1, and length of zones: feed 10D, compression 3D, metering 12D) with four electrically heated zones,

- specially designed annular extrusion die, firstly introduced in [7],

- photo camera Dimage Z3 model (Konica Minolta, Japan) with high resolution (4 Mpx) placed on a tripod near the die exit $\left(45^{\circ}\right.$ turn against direction of extrusion) for die exit visualization,

- draw-off mechanism. 


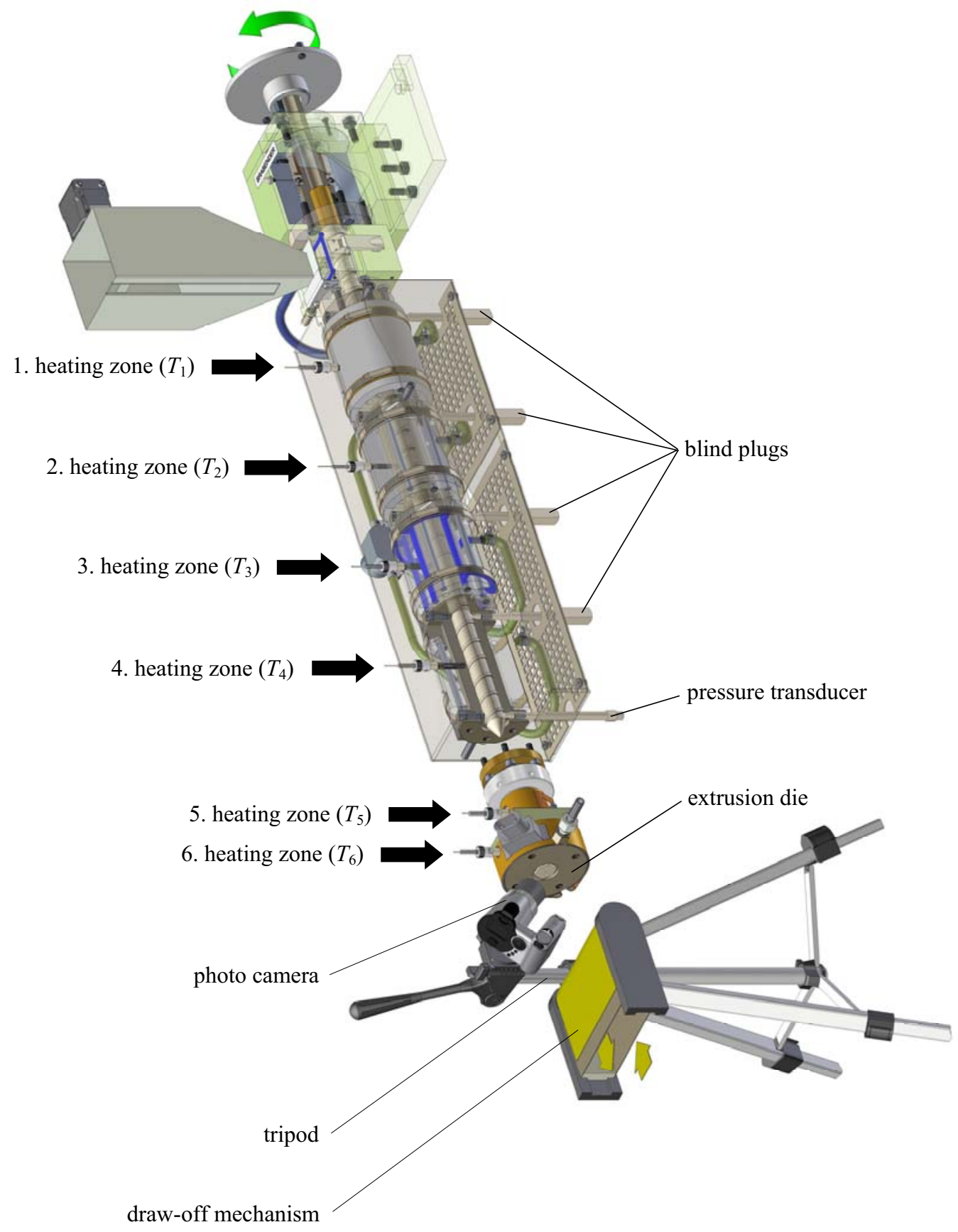

FIGURE 4. Schematic 3D view of laboratory extrusion line in experimental configuration (in scale). 
In our experiments, the extruder zones were heated on the following temperatures (from the hopper to the die): $T_{1}=150^{\circ} \mathrm{C}, T_{2}=155^{\circ} \mathrm{C}, T_{3}=160^{\circ} \mathrm{C}$ and $T_{4}=160^{\circ} \mathrm{C}$. The transition annular part between extruder end and extrusion die and also extrusion die were heated on the same temperature $T_{5}=T_{6}=160^{\circ} \mathrm{C}$. This temperature profile was chosen in order to ensure no thermal degradation of extruded polymer melts. All experiments were performed as 10 minutes tests at ten different mass flow rates (ranging from $0.077 \mathrm{~kg} \cdot \mathrm{hr}^{-1}$ up to $0.731 \mathrm{~kg} \cdot \mathrm{hr}^{-1}$, i.e. from $68 \mathrm{~s}^{-1}$ up to $652 \mathrm{~s}^{-1}$ in term of apparent shear rates). Die drool amount was evaluated through direct collection of accumulated material from the die exit face by a tweezer and its weighting on sensitive analytical balance. The experimental drool masses for both HDPEs were then recalculated from weight to a dimensionless build up ratio according to following equation firstly introduced in [6]:

$$
B R=\frac{\dot{B}}{\dot{m}}
$$

where $\dot{m}$ is total mass flow rate of extruded polymer melt and $\dot{B}$ means build up rate:

$$
\dot{B}=\frac{B}{t_{\mathrm{e}}}
$$

where $B$ is the mass of accumulated die drool material on the die exit face and $t_{\mathrm{e}}$ is total extrusion time of each test (10 minutes in our case).

Furthermore, to ensure the reproducibility of the measurements barrel, screw and all parts of the extrusion die have been perfectly manually cleaned before each single die drool measurement.

\section{Results and Discussion 1}

The experimental results of die drool measurements are provided in Figures 5-7. From the comparison of drool tendencies of both batches it is clear that HDPE Liten FB 29 E2009 54987937 generates much lower level of drool than HDPE Liten FB 29 E2009 32204479 . It is clearly visible that the polymer with low elasticity and shear viscosity generates lower level of drool, which is in good agreement with the previously published results [11]. Moreover, the build up ratio vs. shear rate dependence for HDPE Liten FB 29 E2009 54987937 and the second batch is linear and non-linear, respectively (after first scalable drool appearance at apparent shear rate of $216 \mathrm{~s}^{-1}$ ). Highly non-linear character of this dependence for the second HDPE batch can be explained by the competition between build up rate and peeling of drool from the die by "high speed" extrudate. Die drool phenomenon is visualized for both samples at different apparent shear rates in Figure 6.

In order to explain such large difference in drool intensities between two batches of one HDPE polymer melt, apparent wall shear stresses as a function of apparent shear rate were calculated from pressures measured during each single test. The results are depicted in Figure 7. As can be seen, material with high level of drool (HDPE Liten FB 29 E2009 3220 4479) generates well-known slip-stick instability at significantly lower apparent shear rates than the second batch. Further, appearance and intensity of 
slip-stick instability correlates with appearance and intensity of die drool. This finding indicates that during pressure oscillations in the extrusion die low molecular species of extruded polymer melt starting to separate then they are pushed towards to the wall and finally, build up at the die exit face as unwanted drool mass.

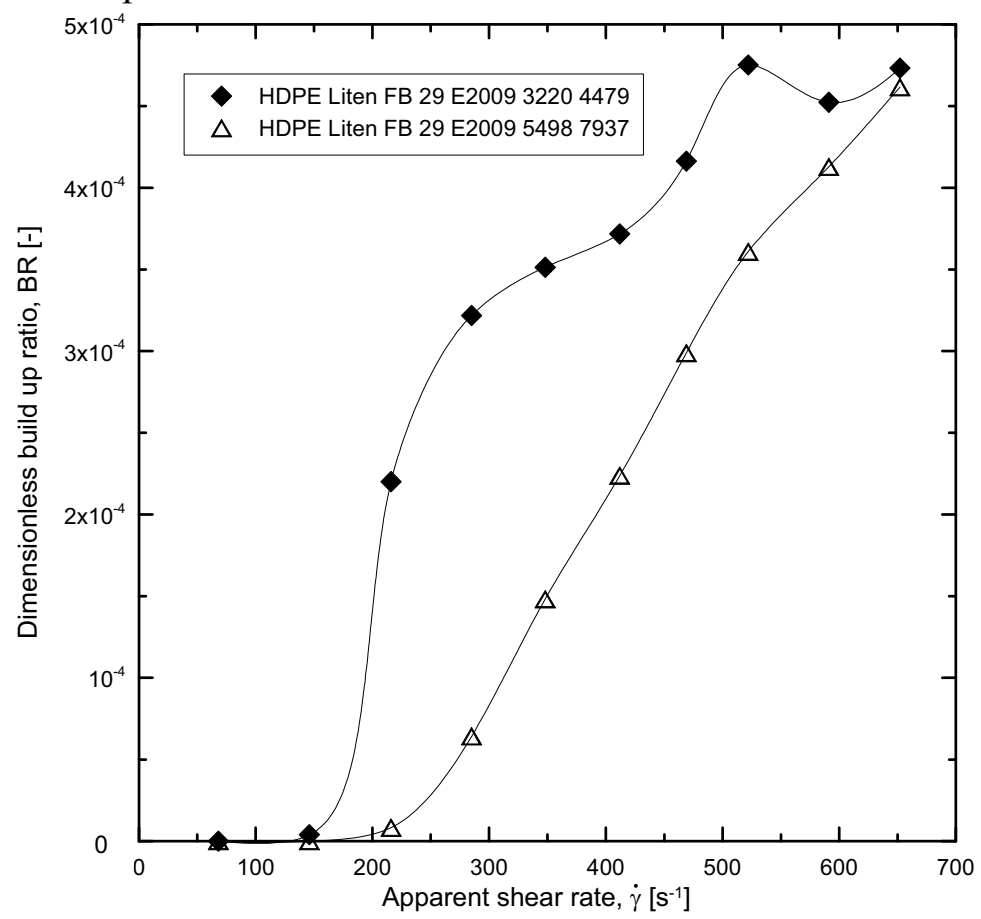

FIGURE 5. Drool tendencies of both investigated HDPEs.
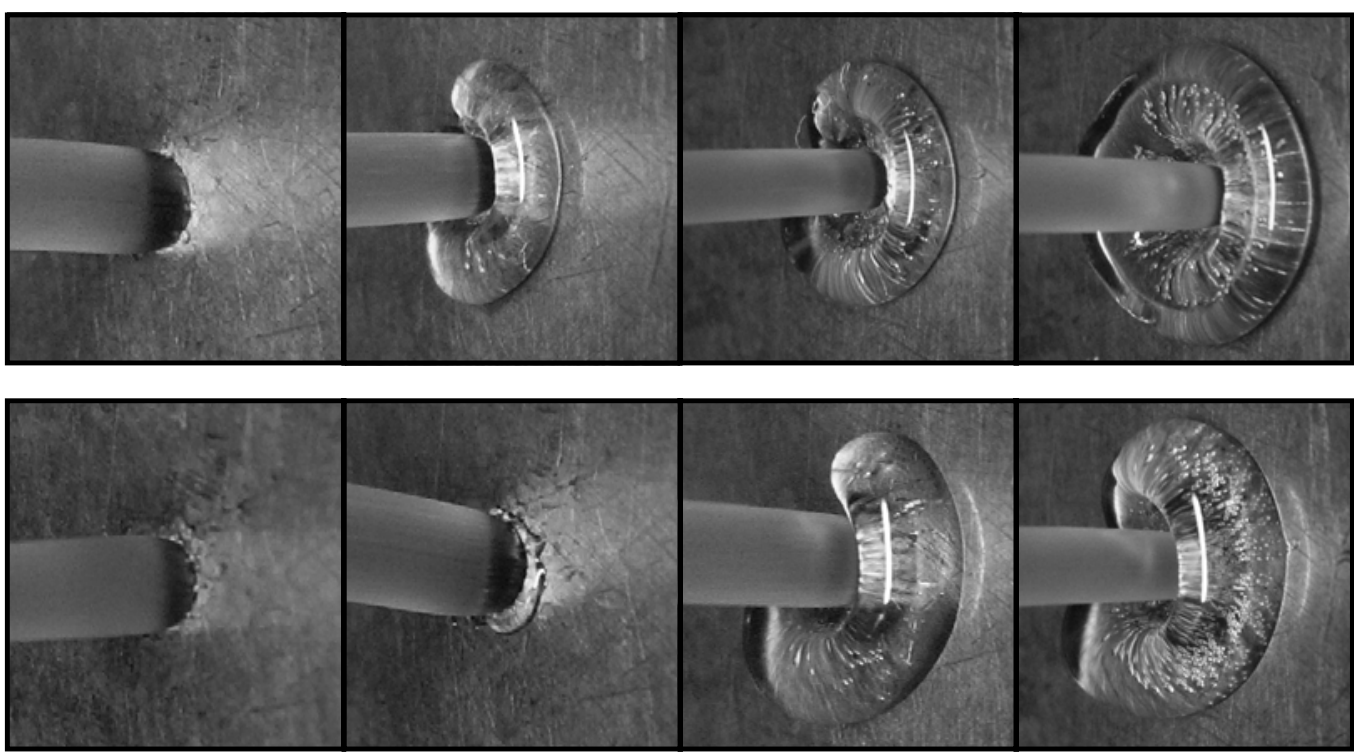

FIGURE 6. Die exit face visualization during die drool experiments. HDPE Liten FB 29 E2009 3220 4479 (top) and HDPE Liten FB 29 E2009 54987937 (bottom) at chosen different apparent shear rates (from the left to the right): $68 \mathrm{~s}^{-1}, 216 \mathrm{~s}^{-1}, 412 \mathrm{~s}^{-1}$, and $652 \mathrm{~s}^{-1}$. 


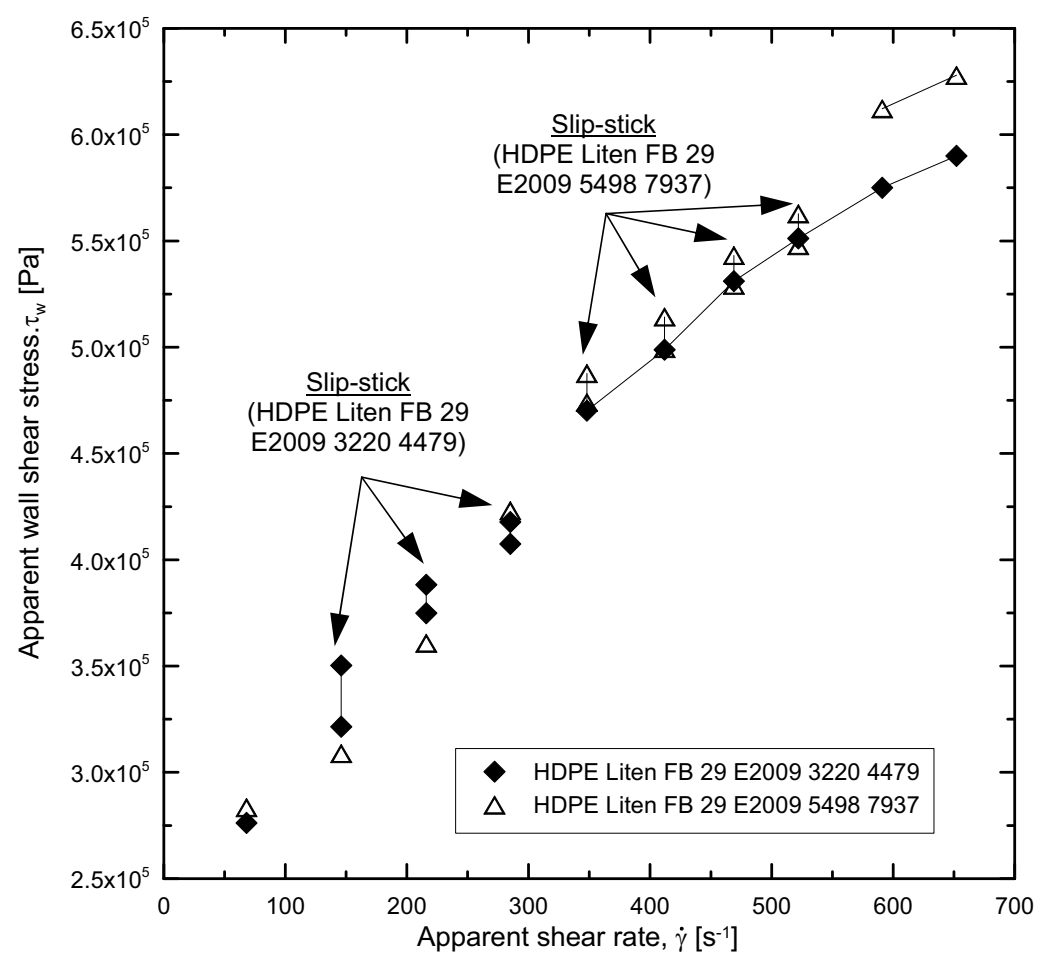

FIGURE 7. Apparent wall shear stresses for each single die drool experiment.

\section{Flow Birefringence Measurements}

Birefringence is a powerful tool for investigation of flow instabilities. The basic idea of this technique (in detail described in $[19,20]$ ) is visualization of stresses inside the polymer melt with the aid of polarized light. If this light goes through a flowing melt, fringes representing stress level in given place appear.

Detailed slip-stick study for both investigated HDPE polymer melts were performed on a special flow visualization laboratory extrusion line consisted from:

- conventional Betol BK38 (Davis-Standard, UK) single screw extruder with diameter of $38 \mathrm{~mm}$ and length of 30D with four electrically heated zones,

- specially designed flow visualization cell equipped by two replaceable inside-die steel inserts, two side strain-free borosilicate glass windows and one pressure transducer in range of 1,500 PSI (10.3421 MPa),

- 3D moveable optical bench (schematic 3D view is provided in Figure 8) containing light source (mercury vapour lamp with wavelength $\lambda=546 \mathrm{~nm}$ ), polariser plate, two quarter wave plates (between them is placed visualization cell), analyser plate, colour filter and CCD analog video camera (Pulnix PEC 3010 model with resolution of $720 \times 576$ pixels) equipped by Nikon lens, extension tube of $197 \mathrm{~mm}$ length and,

- video recorder for capturing birefringence movies on analog tape (25 frames per second). 


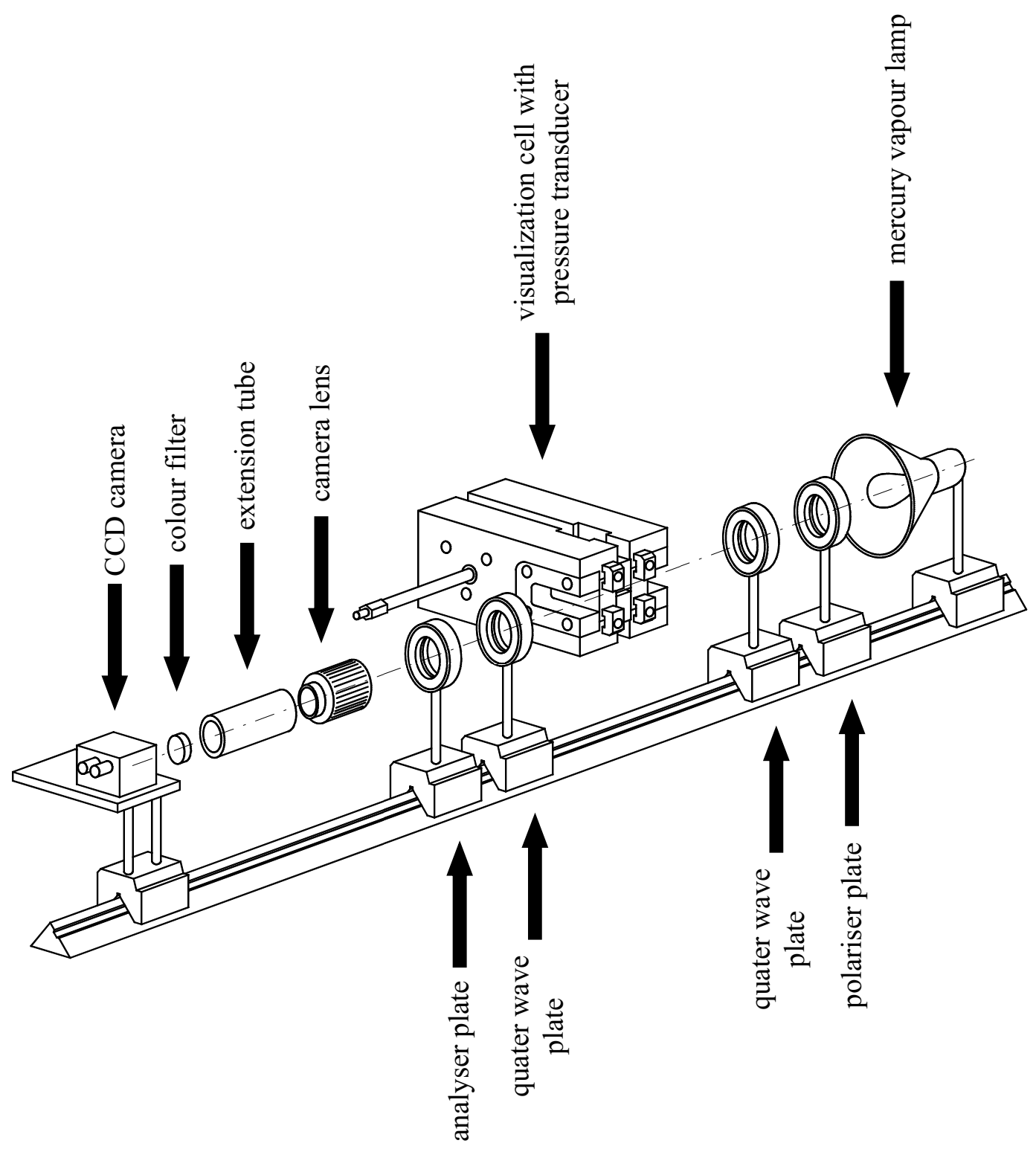

FIGURE 8. Schematic view of optical bench for flow visualization experiments (not in scale).

All flow visualization experiments were carried out under following conditions. Extruder zones were heated on temperatures (from the hopper to the die): $T_{1}=150^{\circ} \mathrm{C}$, $T_{2}=160^{\circ} \mathrm{C}, T_{3}=160^{\circ} \mathrm{C}$ and $T_{4}=160^{\circ} \mathrm{C}$, respectively. Two transition parts between extruder and visualization cell as well as visualization cell were heated on $150^{\circ} \mathrm{C}$. Flow visualization experiments were performed as 5 minutes tests at 31 different mass flow rates for detailed investigation of well-known slip-stick region. These rates ranging from $0.25 \mathrm{~kg} . \mathrm{hr}^{-1}$ up to $1.51 \mathrm{~kg} \cdot \mathrm{hr}^{-1}$ (i.e. from $55 \mathrm{~s}^{-1}$ up to $290 \mathrm{~s}^{-1}$ in term of apparent shear rates). 
Experimental flow geometry formed by two inside-die steel inserts is shown in Figure 9. Contraction ratio is 16:1 and the dimensions are following: upstream channel depth $\mathrm{H}=15 \mathrm{~mm}$, slit width $\mathrm{W}=10 \mathrm{~mm}$, slit gap $\mathrm{G}=0.9375 \mathrm{~mm}$ and slit length $\mathrm{L}=15 \mathrm{~mm}$.

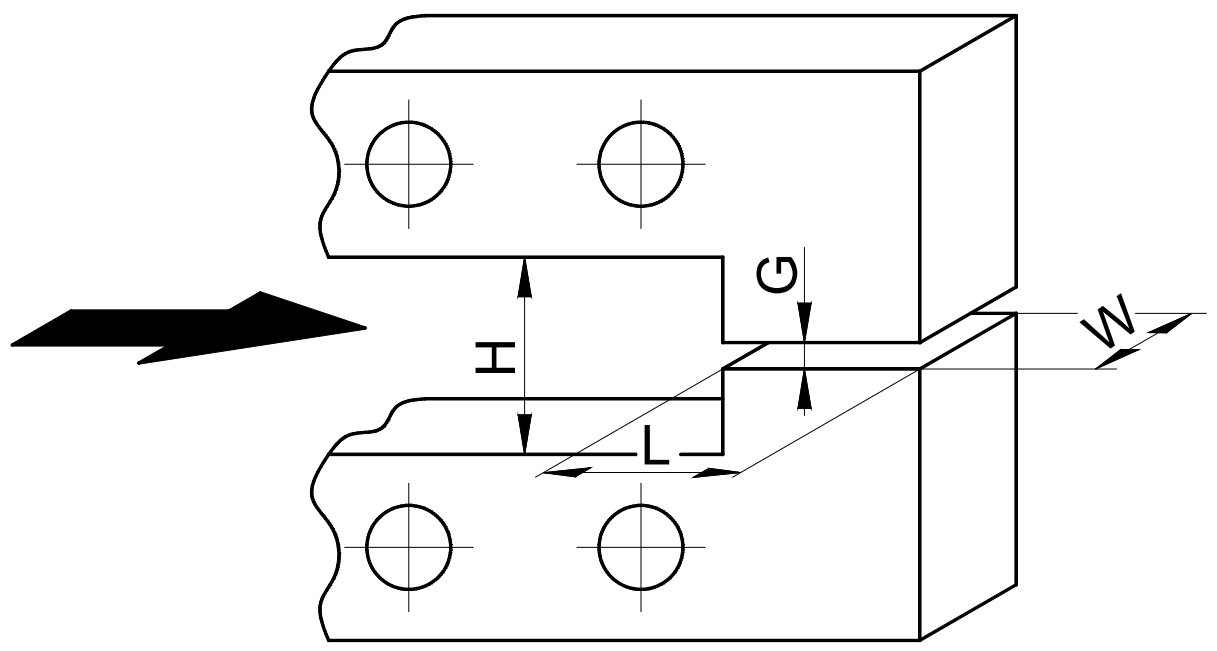

FIGURE 9. Schematic view of two inside-die steel inserts determining flow geometry (not in scale).

Further, in order to compare pressure and stress oscillations inside the visualization cell, well-known stress-optical coefficients (SOC) [21] representing relation between fringe order and stress in given place inside the die were determined for both polymer melts (see Table 1).

TABLE 1. Stress-optical coefficients (SOC) for both investigated polymer melts.

\begin{tabular}{lcc}
\hline Material & $\begin{array}{c}\text { Die temperature } \\
\left({ }^{\circ} \mathbf{C}\right)\end{array}$ & $\begin{array}{c}\text { Stress-optical coefficient (SOC) x 10 } \\
\left(\mathbf{m}^{\mathbf{2}} \mathbf{. N}^{-\mathbf{1}}\right)\end{array}$ \\
\hline HDPE Liten FB 29 & 150 & 2.27 \\
E2009 3220 4479 & 150 & 1.90 \\
\hline HDPE Liten FB 29 & 150 & \\
E2009 5498 7937 & & \\
\hline
\end{tabular}

\section{Results and Discussion 2}

The Figure 10 shows the apparent wall shear stress as the function of the apparent shear rate for both tested samples determined on the flow visualization cell. In order to evaluate the level of apparent wall shear stress oscillation at the slip-stick region, the apparent wall shear stress difference at given apparent shear rate was utilized

$$
\Delta \tau_{\mathrm{w}}(\dot{\gamma})=\tau_{\mathrm{w}, \mathrm{MAX}}(\dot{\gamma})-\tau_{\mathrm{w}, \mathrm{MIN}}(\dot{\gamma})
$$


where $\tau_{\mathrm{w}, \mathrm{MAX}}(\dot{\gamma})$ and $\tau_{\mathrm{w}, \mathrm{MIN}}(\dot{\gamma})$ represents the maximum and minimum wall shear rate, respectively, at the given apparent shear rate.

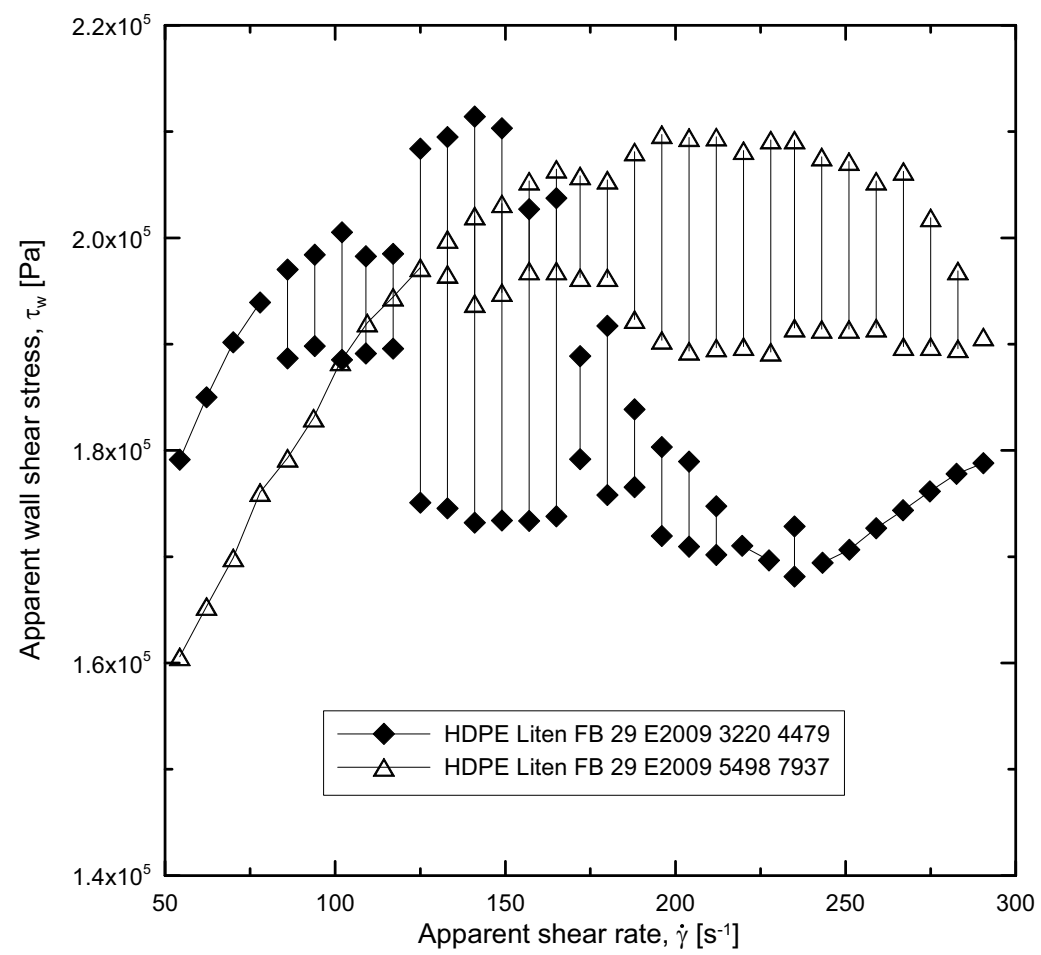

FIGURE 10. Apparent wall shear stresses as a function of apparent shear rates for both batches.

The apparent wall shear stress difference as the function of apparent shear rate is depicted in Figure 11 for both tested samples. It is obvious that HDPE Liten FB 29 E2009 32204479 shows much higher apparent wall shear stress difference than HDPE Liten FB 29 E2009 5498 7937. In more detail, for the first and second sample, the maximum in $\Delta \tau_{\mathrm{w}}(\dot{\gamma})$ (occurs at $141 \mathrm{~s}^{-1}$ and $204 \mathrm{~s}^{-1}$ which correlates nicely with the die drool onset (see Figure 5). Time evolution of pressure oscillations for both samples at these two apparent shear rates is provided at Figure 12. From this figure, it can be concluded that more drooling sample (HDPE Liten FB 29 E2009 3220 4479) shows pressure waves having lower frequency and higher amplitude in comparison with less drooling sample.

In work of Robert et al. [16] focused on slit entry region is possible to find a conclusion that periodic birefringence fringes oscillations are with the same period as the pressure oscillations. We conclude the same for inside slit region and Figures 13 and 14 shows this. The wall shear stress frequency determined from the stress optical law follows the measured pressure oscillations which justify using the stress field measurement to investigate the flow in the slit channel in the slip-stick region with respect to die drool phenomenon. The Figure 15 shows that at the beginning of the slip stick region for HDPE Liten FB 29 E2009 32204479 (at apparent shear rate $110 \mathrm{~s}^{-1}$ ), 
fringe decomposition (or wavy fringe) seem to periodically occur at the die wall, which could indicate separation of low molecular species from basic material.

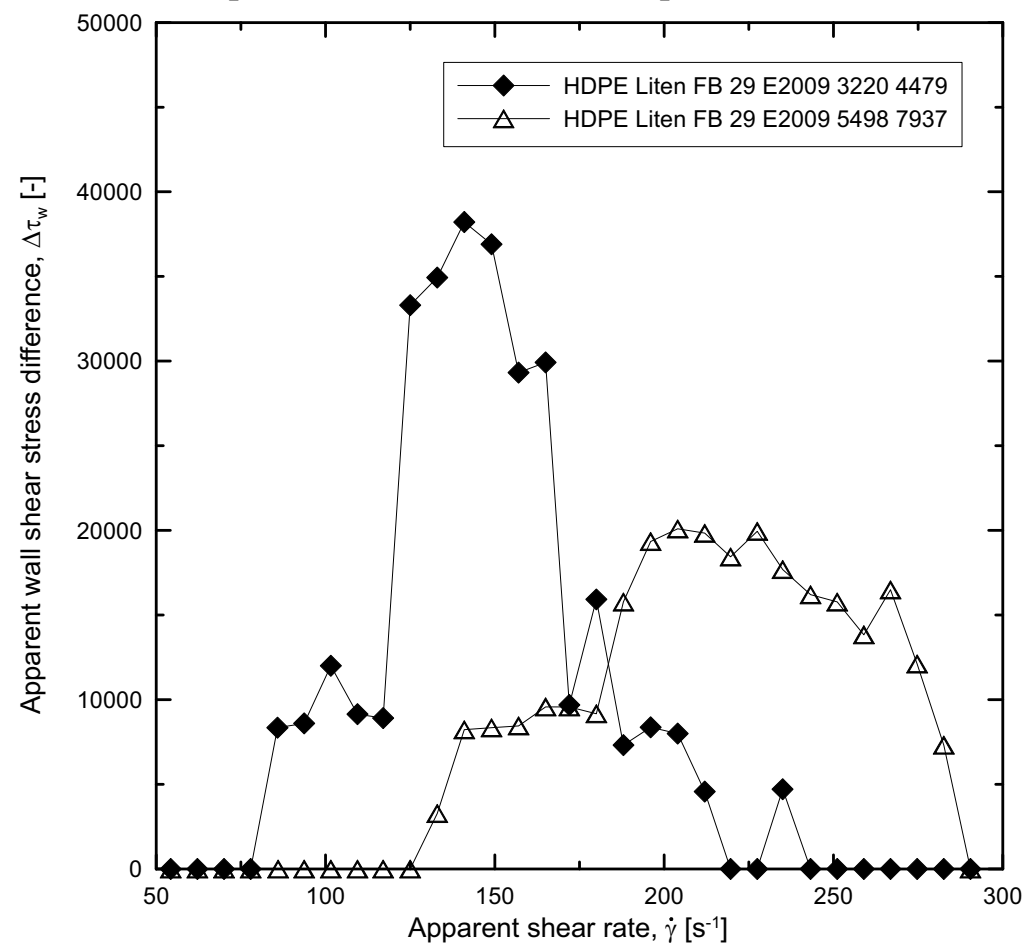

FIGURE 11. Stress difference as a function of apparent shear rate.

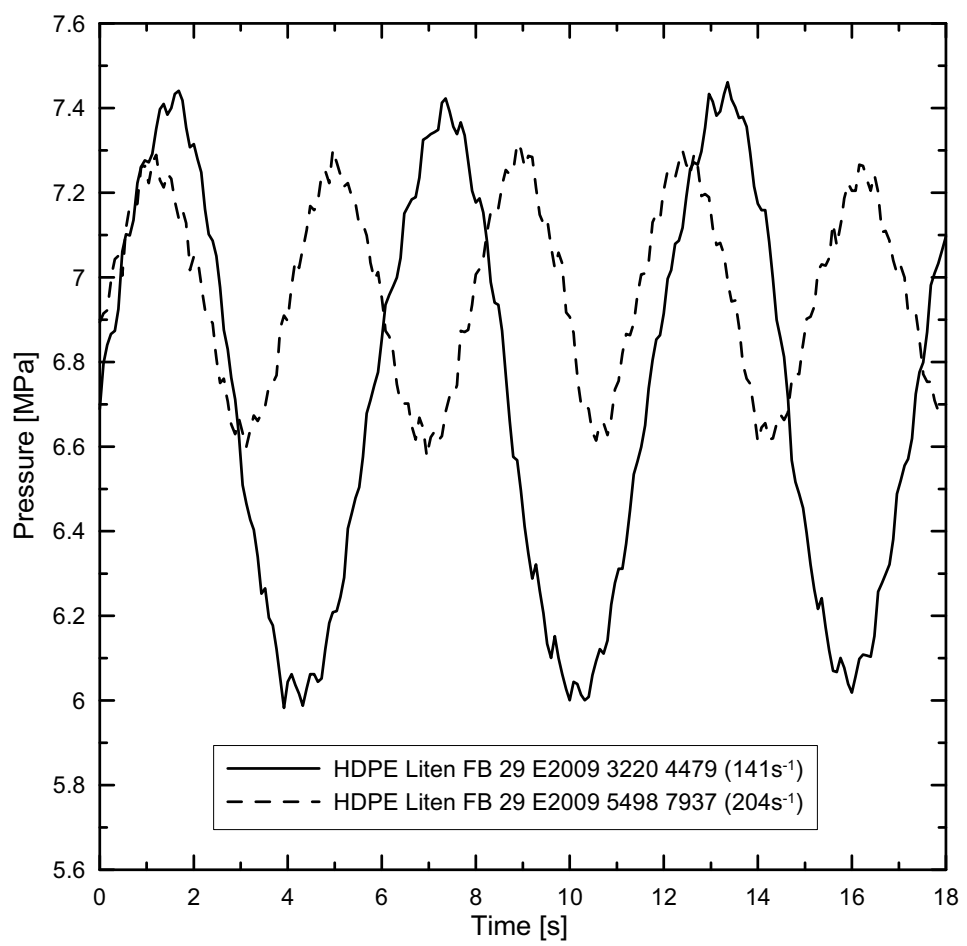

FIGURE 12. Pressure data for shear rate with maximum oscillations. 
a)

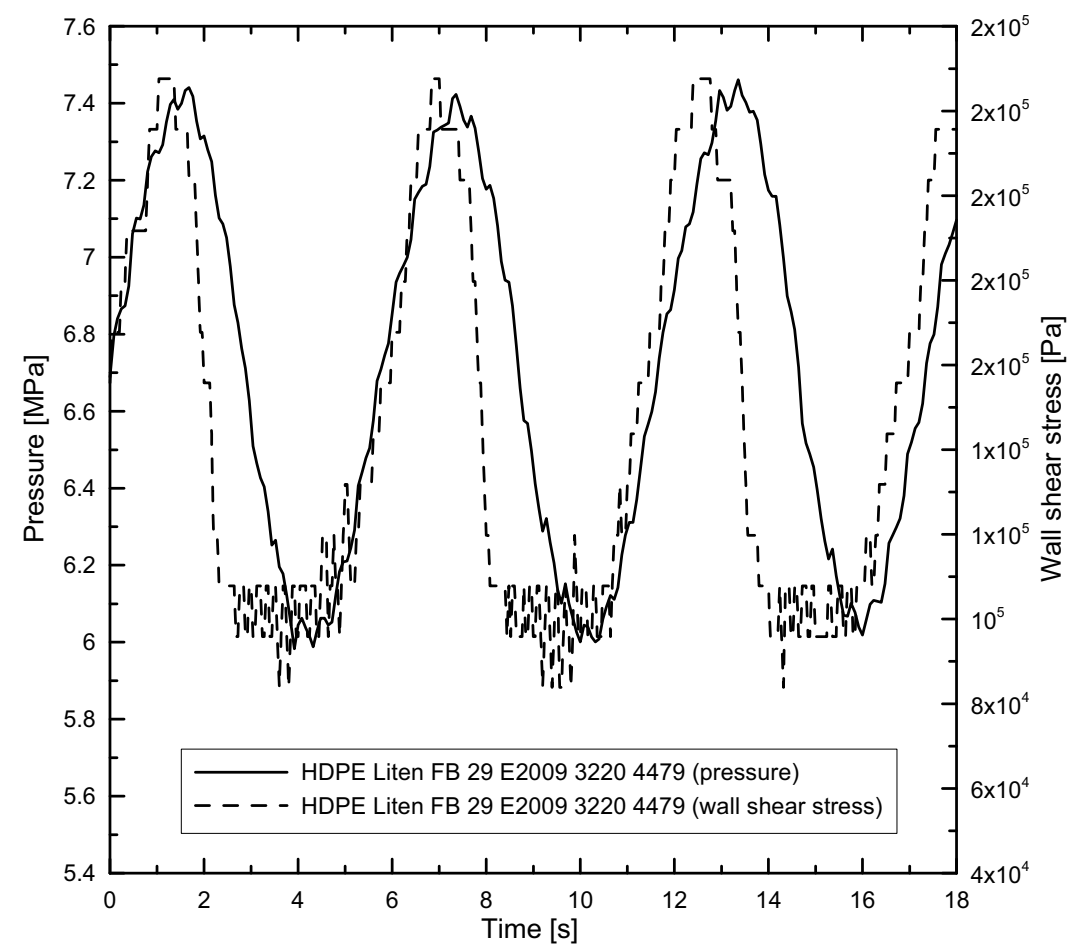

b)

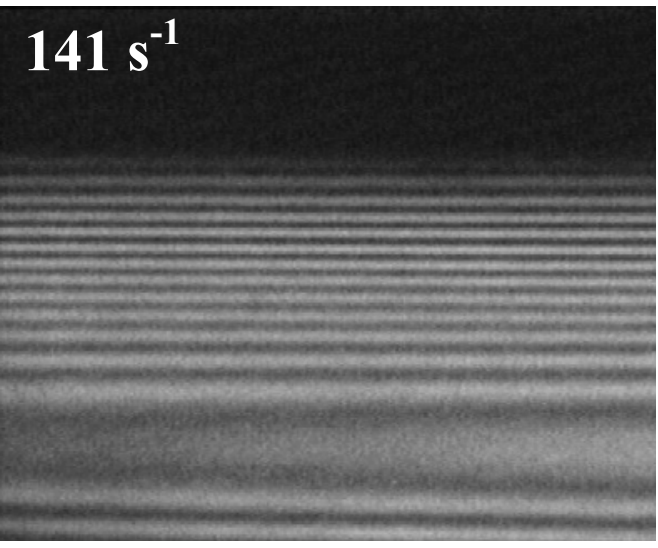

c)

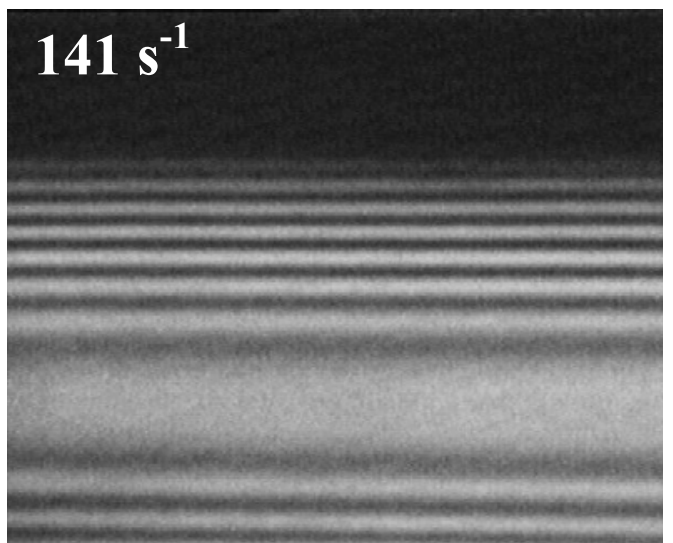

FIGURE 13. Maximum pressure/wall shear stress/fringe oscillation for HDPE Liten FB 29 E2009 3220

4479 sample occurring at the apparent shear rate $141 \mathrm{~s}^{-1}$. 13a) Time evolution of pressure/wall shear stress oscillations. 13b) Fringe order at the stress maximum. 13c) Fringe order at the stress minimum. 
a)

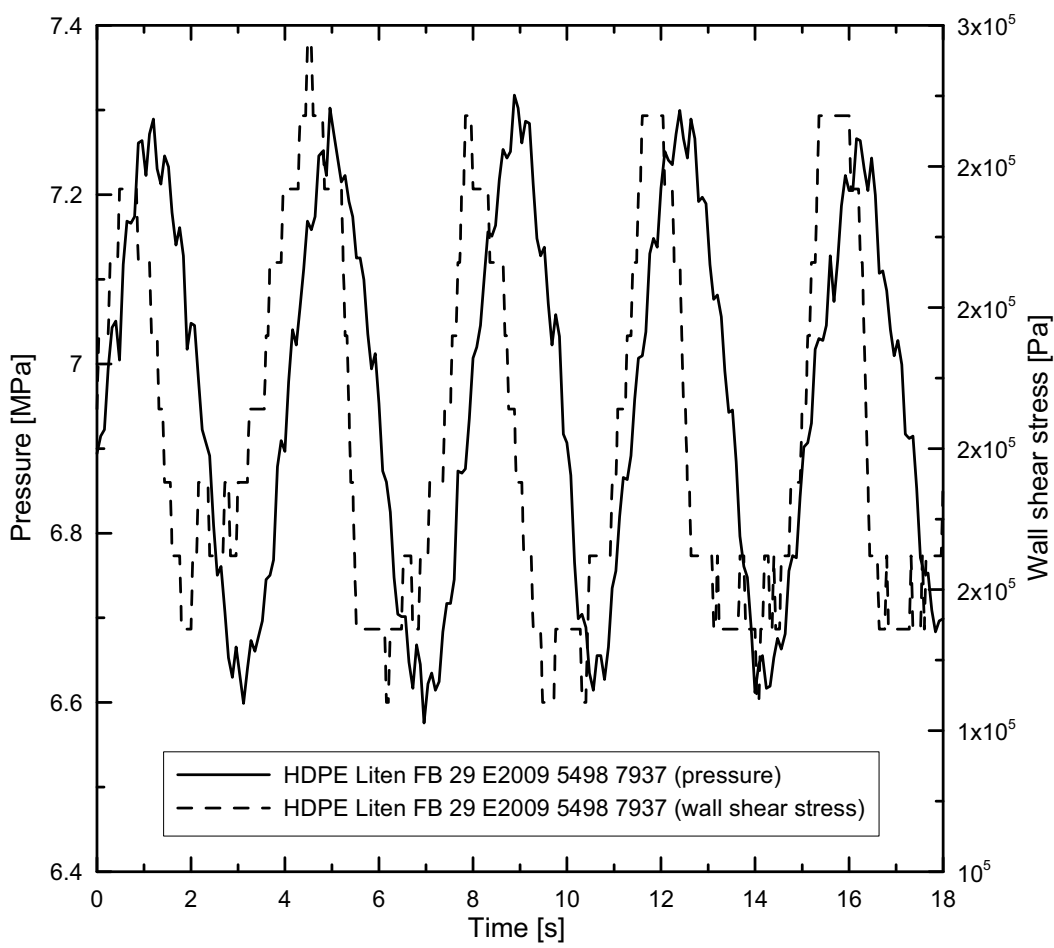

b)

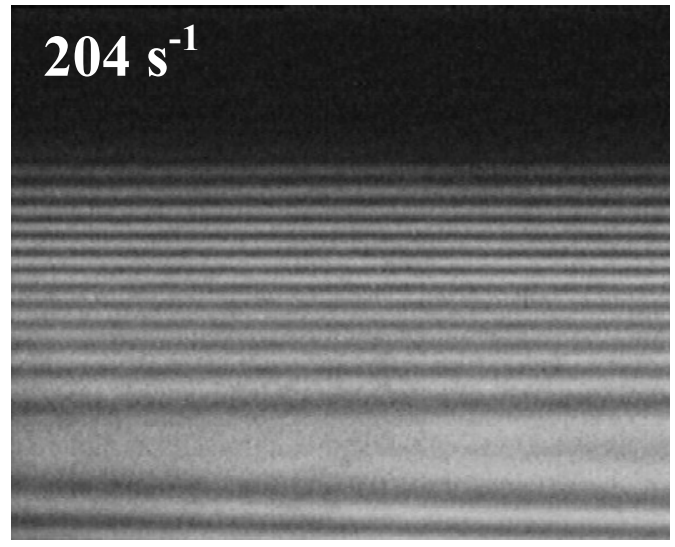

c)

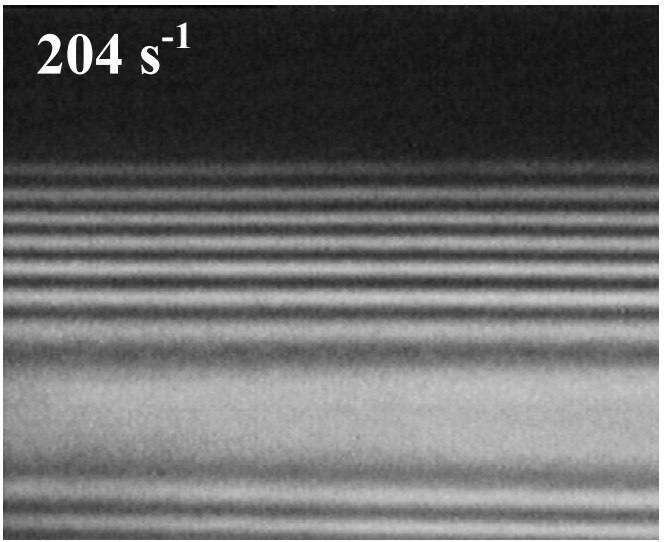

FIGURE 14. Maximum pressure/wall shear stress/fringe oscillation for HDPE Liten FB 29 E2009 5498 7937 sample occurring at the apparent shear rate $204 \mathrm{~s}^{-1}$. 14a) Time evolution of pressure/wall shear stress oscillations. 14b) Fringe order at the stress maximum. 14c) Fringe order at the stress minimum. 

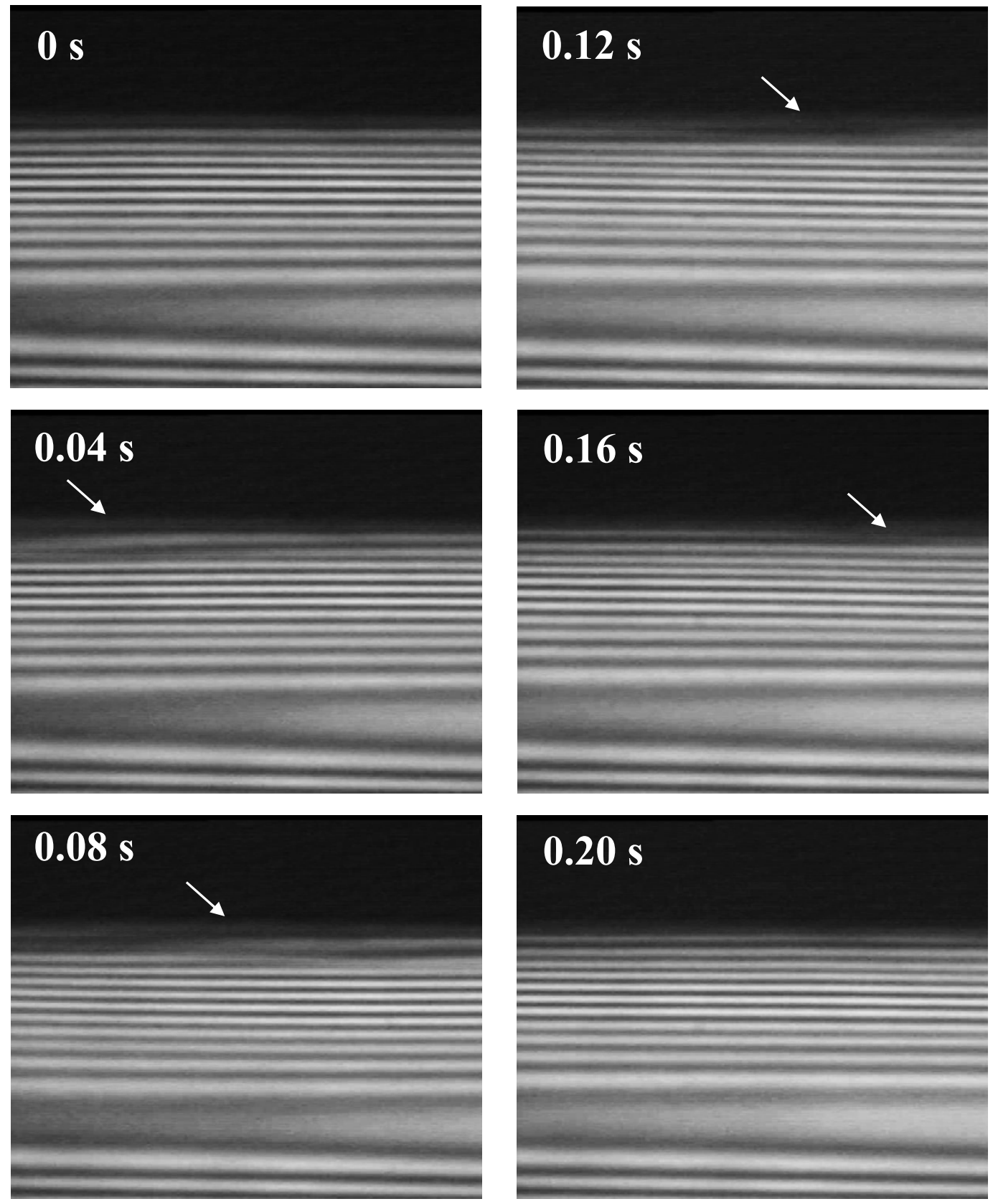

FIGURE 15. Flow visualization images for HDPE Liten FB 29 E2009 3220447 at one apparent shear rate $\left(110 \mathrm{~s}^{-1}\right)$ in different duration times with local deformation of fringes near the die wall indicating separation of low molecular species from basic material. 
At the super flow regime i.e. above the slip-stick region, the flow seems to be locally unstable because the fringes start to have wavy character (see Figure 16). In more detail, the sample HDPE Liten FB 29 E2009 32204479 producing the higher amplitude of the wavy fringe has higher sensitivity to the die drool phenomenon in comparison with the second tested sample HDPE Liten FB 29 E2009 54987937.
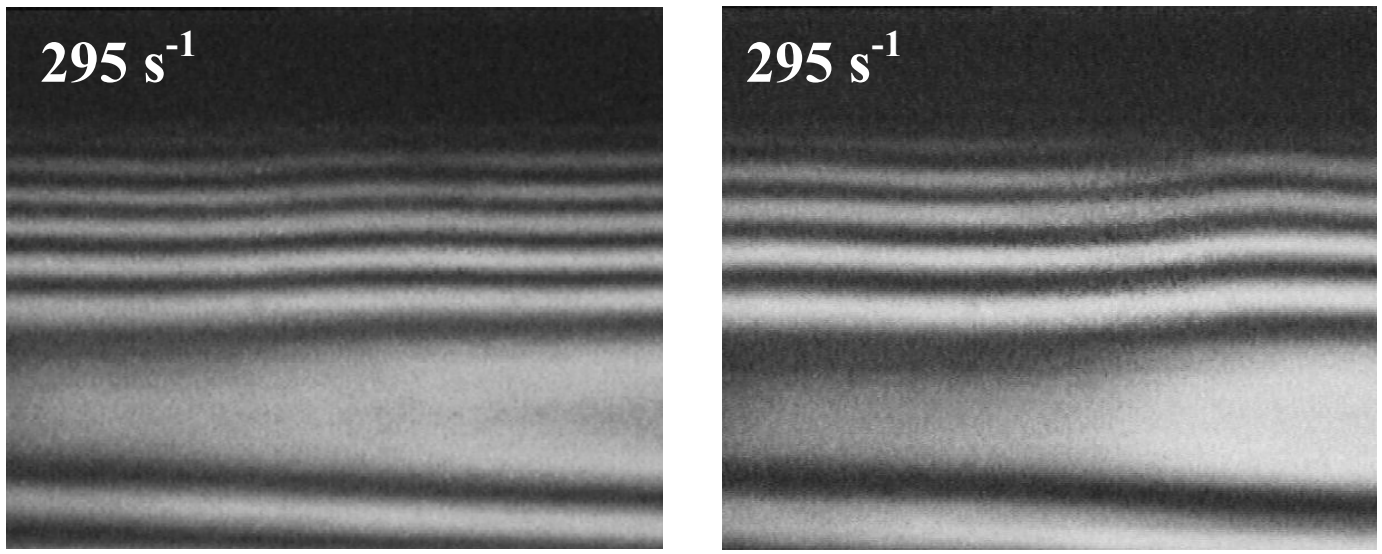

FIGURE 16. Flow visualization images for HDPE Liten FB 29 E2009 54987937 (left) and HDPE Liten FB 29 E2009 32204479 (right) at wave deformation of fringes in super flow.

These preliminary results indicate that the stress field measurements by using birefringence technique could be considered as the useful tool to understand the die drool phenomenon in more detail.

\section{CONCLUSION}

In this work, it has been experimentally found that for HDPE polymer the die drool phenomenon decreases with decreased elasticity $\left(N_{1}\right)$ and shear/extensional viscosities. Further, good correlation between appearance and intensity of both die drool and slip-stick phenomena have been discovered. Finally, it has been suggested that the stress field measurements by using birefringence technique and flow visualization cell can be considered as the useful tool to investigate die drool phenomenon.

\section{ACKNOWLEDGMENTS}

This work has been supported by the internal grant of TBU in Zlín No. IGA/2/FT/11/D funded from the resources of specific university research.

This article was written with support of Operational Program Research and Development for Innovations co-funded by the European Regional Development Fund (ERDF) and national budget of Czech Republic, within the framework of project Centre of Polymer Systems (reg. number: CZ.1.05/2.1.00/03.0111). 
Further, authors thank Steve Brook, Ian Smith and Roy Dixon from University of Bradford for technical support during flow visualization experiments.

Finally, special acknowledgement is directed Roman Kolařík from Tomas Bata University in Zlín for his immense help during many complete manual cleaning procedures of laboratory extruder before each single die drool measurement.

\section{REFERENCES}

1. R. B. Bird, R. C. Armstrong and O. Hassager, Dynamics of Polymer Liquids Vol. 1, New York: Wiley, 1997.

2. R. I. Tanner, Engineering Rheology, Oxford: Clarendon, 1985.

3. S. V. Hatzikiriakos and K. B. Migler, Polymer Processing Instabilities: Control and Understanding, New York: Marcel Dekker, 2005.

4. I. Klein, Plastics World 39, 112-113 (1981).

5. J. D. Gander and A. J. Giacomin, Polym. Eng. Sci. 37, 1113-1126 (1997).

6. F. Ding, L. Zhao, A. J. Giacomin and J. D. Gander, Polym. Eng. Sci. 40, 2113-2123 (2000).

7. K. Chaloupková and M. Zatloukal, Polym. Eng. Sci. 47, 871-881 (2007).

8. K. Chaloupková and M. Zatloukal, Polym. Eng. Sci. 111, 1728-1737 (2009).

9. T. A. Hogan, P. Walia and B. C. Dems, Polym. Eng. Sci. 49, 333-343 (2009).

10. P. K. Dhori, R. S. Jeyaseelan, A. J. Giacomin and J. C. Slattery, J. Non-Newtonian Fluid Mech. 71, 231-243 (1997).

11. J. Musil and M. Zatloukal, AIP Conference Proceedings 1152, 69-74 (2009).

12. J. Musil and M. Zatloukal, Chem. Eng. Sci. 65, 6128-6133 (2010).

13. M. Zatloukal and J. Musil, Annual Technical Conference-ANTEC, Conference Proceedings 1, 748-751 (2010).

14. S. G. Hatzikiriakos and J. M. Dealy, J. Rheol. 36, 845-884 (1992).

15. M. M. Denn, Ann. Rev. Fluid Mech.. 33, 265-287 (2001).

16. L. Robert, B. Vergnes and Y. Demay, J. Non-Newtonian Fluid Mech. 112, 27-42 (2003).

17. H. Münstedt, M. Schmidt and E. Wassner, J. Rheol. 44, 413-427 (2000).

18. O. Kulikov and K. Hornung, J. Non-Newtonian Fluid Mech. 124, 103-114 (2004).

19. G. G. Fuller, Optical Rheometry of Complex Fluids, New York: Oxford University Press, 1995.

20. H. Janeschitz-Kriegel, Polymer Melt Rheology and Flow Birefringence, New York: Springer-Verlag, 1983.

21. M. T. Martyn, C. Nakason and P. D. Coates, J. Non-Newtonian Fluid Mech. 91, 123-142 (2000). 
Copyright of AIP Conference Proceedings is the property of American Institute of Physics and its content may not be copied or emailed to multiple sites or posted to a listserv without the copyright holder's express written permission. However, users may print, download, or email articles for individual use. 